Proceedings of the 42th Annual Conference of the IEEE Industrial Electronics Society (IECON 2016), Florence, Italy, October 24-27, 2016.

\title{
Power Transformer for a Single-stage Bidirectional and Isolated AC-DC Matrix Converter for Energy Storage Systems
}

D. Varajão

L. M. Miranda

R. E. Araújo

J. P. Lopes

(C) 2016 IEEE. Personal use of this material is permitted. Permission from IEEE must be obtained for all other uses, in any current or future media, including reprinting/republishing this material for advertising or promotional purposes, creating new collective works, for resale or redistribution to servers or lists, or reuse of any copyrighted component of this work in other works.

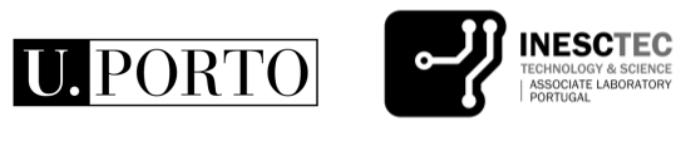




\title{
Power Transformer for a Single-stage Bidirectional and Isolated AC-DC Matrix Converter for Energy Storage Systems
}

\author{
Diogo Varajão ${ }^{\star \ddagger}$, Luís M. Miranda ${ }^{\star}$, Rui E. Araújo ${ }^{\star \ddagger}$, J. Peças Lopes ${ }^{\star \ddagger}$, \\ ${ }^{\star}$ INESC TEC, ${ }^{\ddagger}$ Faculty of Engineering of the University of Porto \\ dvarajao@inesctec.pt,luis.m.miranda@inesctec.pt, raraujo@fe.up.pt, jpl@fe.up.pt
}

\begin{abstract}
This paper presents an approach to design the transformer and the link inductor for the high-frequency link matrix converter. The proposed method aims to systematize the design process of the HF-link using analytic and software tools. The models for the characterization of the core and winding losses have been reviewed. Considerations about the practical implementation and construction of the magnetic devices are also provided. The software receives the inputs from the mathematical analysis and runs the optimization to find the best design. A 10 $\mathrm{kW} / 20 \mathrm{kHz}$ transformer plus a link inductor are designed using this strategy achieving a combined efficiency of $99.32 \%$.
\end{abstract}

Index Terms-Power transformers, magnetic design, litz-wire, ferrites, AC-DC power converters, matrix converters, battery charger, energy storage, electric vehicles.

\section{INTRODUCTION}

D ESIGN of highly-efficient active and passive components for power electronics is crucial to implement a lowcarbon economy. Power electronics is making profoundly changes within the transportation sector [1] and the electric power system [2]. Bidirectional AC-DC converters are required for several applications, such as battery energy storage systems (BESS) [3], chargers for electric vehicles (EVs) [4] and solid-state transformers (SST) [5]. The development of new wide bandgap power semiconductors [6] combined with enhanced modulations and control techniques are contributing for the miniaturization and efficiency improvement of the power electronics converters. This is followed by the increase of the switching frequency of power semiconductors. The consequent change in the frequency spectrum of the current that circulates in the power transformer of these converters requires new design methods to achieve a minimum volume and maximum efficiency in all operating range. Several approaches for the design of a high-frequency (HF) power transformer were proposed in [7]-[20]. Matrix converters (MC) are one of the most interesting families of converters due to its unique and attractive characteristics [21]. By employing an array of controlled four-quadrant power switches the MC enables AC-AC conversion without any intermediate energy storage element [22]. As concluded in [23], [24], the MC can achieve higher power densities for AC-AC and AC-DC conversion when compared with equivalent DC-link based solutions. The high-frequency link matrix converter (HFLMC) proposed in [25] is a single-stage bidirectional and isolated AC-DC energy conversion system. By exploring the attributes of the MCs, the circuit volume and weight can be reduced, and a longer service life is expected when compared with existing technical solutions [26]. In this paper is described the design process of the HF power transformer (HFT) and the link inductor for the HFLMC. The manuscript is organized as follows: section II the topology and the modulation strategy for the HFLMC are briefly described. The core loss modeling and winding loss modeling are presented in section III and section IV respectively. Finally, the detailed design of the power transformer and the link inductor is presented in section $\mathrm{V}$ and section VI respectively.

\section{High-FREQUenCy LinK MATRIX CONVERTER}

Fig. 1 shows circuit schematic of the HFLMC. Each bidirectional switch $S_{x y}$ is composed by two transistors $S_{x y 1}$ and $S_{x y 2}(x=a, b, c$ and $y=P, N)$ in a common-source configuration. The MC applies voltage $v_{p}$ to the transformer. The FB produces $i_{o}$ by impressing $v_{s}$ in the HFT's secondary winding. An output filter reduces the ripple in DC current, $i_{d c}$, that charges and discharge the battery pack. The HFL operation requires an $\mathrm{AC}$ voltage with balanced positive and negative volt-seconds at the transformer terminals. Following this requirement, the proposed modulation for the HFLMC combines the space vector approach with phase-shift modulation (PSM), as described in [25]. This allows the operation of the converter using the same principle as for dual active bridge (DAB). Active and reactive power can be independently controlled (PQ control) as well the dc current, as demonstrated in [26]. Fig. 2 depicts the voltages applied to the transformer and the resulting current during one period of modulation, $T_{s}$. The voltage difference between $v_{p}$ and $v_{s}$ is applied to the transformer which stores energy in its leakage inductances. Therefore, the equivalent inductance, $L$, serves as the main energy transfer element. Design a transformer with a specific leakage inductance is very complex. The typical design and construction methods used in power magnetics are oriented to minimize the leakage inductance and it is not often a design variable. An alternative approach is to design the transformer with the minimum leakage inductance and add an external inductor to meet the requirements [27]. Fig. 3 represents an equivalent model of the transformer. Note that in this work all coupling capacitances are neglected. $L_{p}$ and $L_{s}$ are respectively the primary and secondary side leakage 


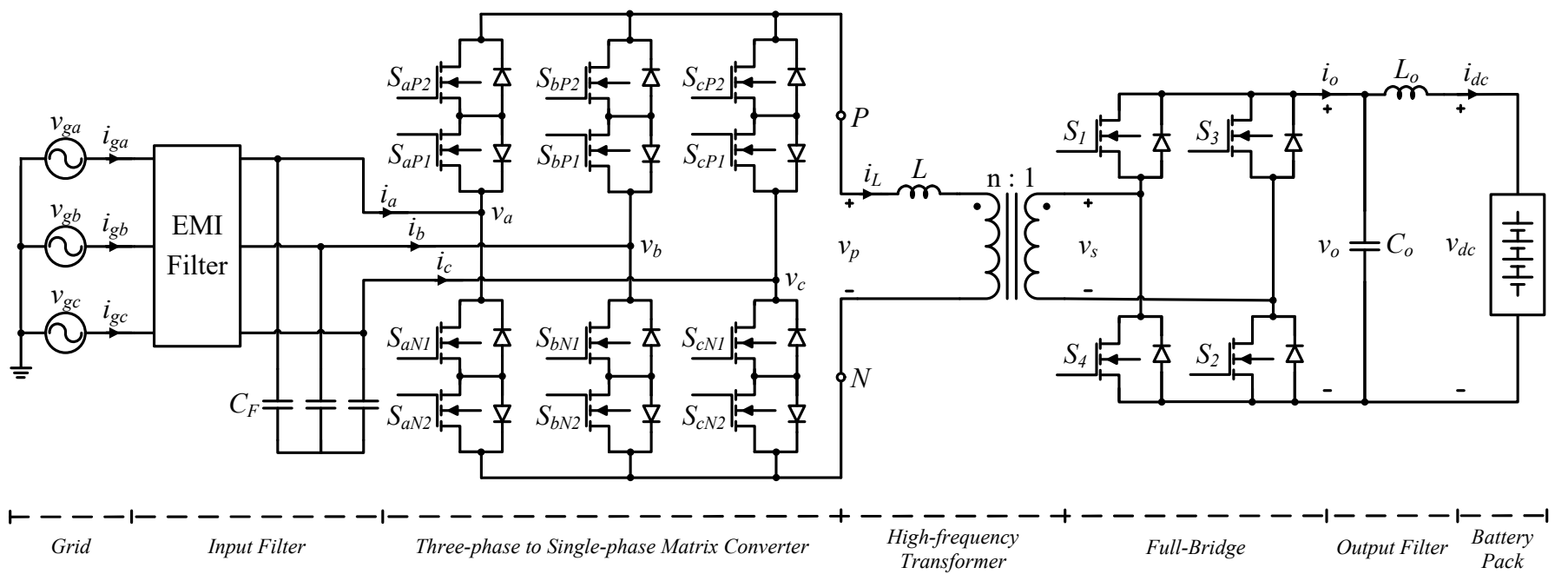

Fig. 1. Circuit schematic of the high-frequency link matrix converter.

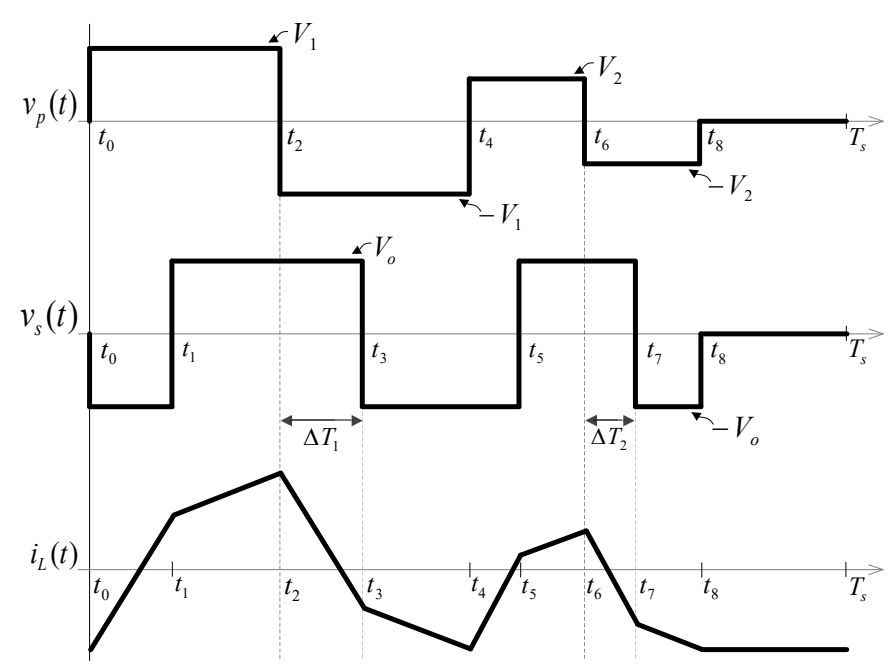

Fig. 2. Modulation principle for positive phase-shift.

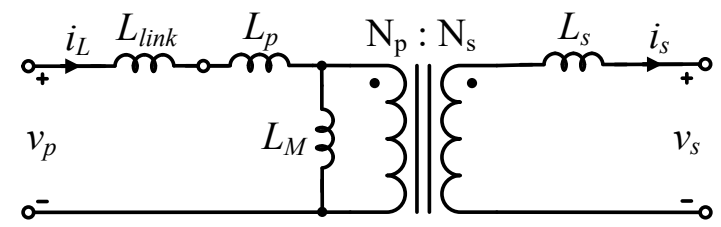

Fig. 3. Equivalent model of the high-frequency transformer.

inductances of the transformer. The magnetizing inductance is characterized by $L_{M}$ referred to the primary side. $L_{\text {link }}$ is the external series inductor added to the transformer for the HF-link operation. The equivalent inductance can be related with $L_{p}, L_{s}$, and $L_{l i n k}$ by:

$$
L=L_{\text {link }}+L_{p}+\left(\frac{N_{p}}{N_{s}}\right)^{2} L_{s}
$$

where $N_{p}$ and $N_{s}$ are the number of turns of the primary and secondary winding, respectively.

\section{CORE LOSS MODELING}

The three main physical loss sources in a magnetic core are the hysteresis losses, eddy-current losses, and residual losses. The $B-H$ characteristic of a core material, also known as the magnetization curve, represent the relation between the flux density and the magnetic field. The energy loss due to hysteresis in the $B-H$ loop is directly proportional to the area inside the magnetization curve and the excitation frequency, $f_{c}$ [28]. The alternating flux in the core drives electrical eddy currents to flow causing losses in the resistance of the core material. These eddy currents typically increase at least as $f_{c}^{2}$ and are particularly significant in HF applications [28]. Moreover, during a phase of constant flux (where the applied voltage across the magnetic component is zero) losses still occur in the core material. According to [14], these residual losses are due to relaxation processes that occur in the core.

The first empirical method to calculate core loss density, $P_{c}$, was proposed by Steinmetz [29]. Core manufacturers provide data of losses per volume that can be used to empirically extract the parameters for the Steinmetz equation. Although, these parameters are only valid for a limited frequency and flux density range [20]. Moreover, the Steinmetz equation is only valid for sinusoidal flux waveforms which is not normally found in power electronics applications [18]. Several models have been developed in order to overcome this limitation and determine losses for a variety of waveforms. The generalized Steinmetz equation (GSE), the improved GSE (iGSE), and the improved iGSE ( $\left.{ }^{2} \mathrm{GSE}\right)$ [14] are examples of these new models. However, the impact of a DC premagnetization (HDC) is not considered in these models. In order to overcome this drawback, core loss measurements could be stored in a core material database for further use in loss calculation [30]. This database, designated by loss map, stores the loss information for different operating points according the peak-to-peak flux density, $f_{c}$, temperature, and the DC bias [31].

The GeckoMAGNETICS [32] software uses a hybrid loss modeling approach by employing the loss map and the $i^{2} \mathrm{GSE}$ 
model. Some loss map operating points are used to extract the Steinmetz parameters for a wide frequency and flux density range. Then, the core losses are calculated using the $\left(i^{2} \mathrm{GSE}\right)$ model that includes the relaxation effects. First, the flux density waveform is separated into its fundamental flux waveform and into piecewise linear flux waveform segments. Then, the loss energy is computed for all segments and combined to represent the total core loss. In this work, the core losses are determined using the design tool provided by the software.

\section{WINDING LOSS MODELING}

Alternating currents induce eddy currents inside the conductor and cause an irregular current distribution. This results in ohmic losses in the winding that can be separated into skin effect losses and proximity effect losses [17]. The skin effect forces the current to flow close to the conductor surface resulting in an increase of the effective resistance. The distance from the outer boundary to where the current density falls to $1 / e$ of the maximum is called the skin depth $\delta_{w}$ and is calculated as:

$$
\delta_{w}=\frac{1}{\sqrt{\pi \cdot \sigma \cdot f_{w} \cdot \mu}}
$$

where $f_{w}$ is the frequency of the sinusoidal current, $\mu$ and $\sigma$ are the magnetic permeability and the electrical conductivity of the conductor material, respectively. For copper conductors, the relative magnetic permeability $\mu_{r}$ can be assumed equal to one. The proximity effect losses are due to eddy currents induced by external magnetic field $H_{e}$. For example, the air gap fringing field or the magnetic field from other conductors lead to the proximity effect. In the case of litz-wire, it is also necessary to consider the internal magnetic field $H_{i}$ induced by each strand in its neighbouring strands [33].

In power electronic applications, usually the voltages and currents are not sinusoidal waveforms. One way of handle non-sinusoidal waveforms is by using Fourier analysis. The effective frequency for a non-sinusoidal current waveform can be calculated as [8]:

$$
f_{\text {eff }}=\frac{1}{2 \pi} \sqrt{\frac{\sum_{j=0}^{\infty} I_{j}^{2} \omega_{j}^{2}}{\sum_{j=0}^{\infty} I_{j}^{2}}}
$$

where $I_{j}$ is the rms amplitude of the Fourier component at frequency $\omega_{j}$. The skin depth at $f_{\text {eff }}$ is a more realistic estimation for the magnetic design process. The effect of eddy currents can be taken in account by the ac copper loss factor, $F_{a c}$, calculated by [17]:

$$
F_{a c}=\frac{R_{a c}}{R_{d c}}=1+\frac{\left(\pi \cdot N_{0} \cdot N\right)^{2} d_{0}^{6}}{192 \cdot \delta_{w}^{4} \cdot c_{b 2}}
$$

where $N$ is the number of turns, $N_{0}$ is the number of strands, $d_{0}$ is the diameter of the copper in each strand, and $c_{b 2}$ is breadth of the window area of the core. This factor relates dc resistance to an ac resistance which accounts for all winding losses. The dc resistance can be determined by the following:

$$
R_{d c}=\frac{M L T \cdot N}{\pi \cdot \sigma \cdot r_{0}^{2} \cdot N_{0}}
$$

where $M L T$ is the mean length per turn of the winding, and $r_{0}$ is the strand radius. Considering $F_{a c}$ and $R_{d c}$, the winding
TABLE I

CONVERTER PARAMETERS AND MAGNETICS TARGET SPECIFICATIONS.

\begin{tabular}{c|c||c|c||c|c}
\hline Parameter & Value & Parameter & Value & Parameter & Value \\
\hline \hline$V_{g, l l}$ & $400 \mathrm{~V}$ & $V_{d c, \text { nom }}$ & $380 \mathrm{~V}$ & $L$ & $44 \mu \mathrm{H}$ \\
\hline$f_{i}$ & $50 \mathrm{~Hz}$ & $I_{d c, \max }$ & $31 \mathrm{~A}$ & $I_{L, n o m}$ & $45 \mathrm{~A}$ \\
\hline$P_{\text {nom }}$ & $10 \mathrm{~kW}$ & $f_{s}$ & $20 \mathrm{kHz}$ & $I_{L, p k}$ & $110 \mathrm{~A}$ \\
\hline$I_{g, \max }$ & $16 \mathrm{~A}$ & $n$ & 1 & $T_{\max }$ & $100^{\circ} \mathrm{C}$ \\
\hline
\end{tabular}

losses can be estimated for a given sinusoidal current with rms amplitude $I_{L, \text { nom }}$ by:

$$
P_{w}=R_{d c} \cdot F_{a c} \cdot I_{L, n o m}^{2} .
$$

\section{DESIGN OF POWER TRANSFORMER}

\section{A. Specifications}

The power transfer between the matrix converter to the full-bridge can be controlled by the amplitude and phaseshift of $v_{p}$ and $v_{p}$. For this analysis, it is considered that the amplitude of these voltages is constant during one period of modulation. In practice, this can be approximately achieved if the switching frequency is sufficiently higher compared to the grid frequency, $f_{i} . V_{1}$ and $V_{2}$ defined in Fig. 2 are the amplitude of the switching space vectors applied by the MC. In turn, $V_{o}$ is the amplitude of the output dc voltage applied by the FB. The resulting power flow from the $\mathrm{MC}$ to the FB over one switching period is given by:

$$
P_{H F T}=\frac{3}{4} \frac{V_{p} V_{s}}{\omega_{s} L} n \phi\left(1-\frac{|\phi|}{\pi}\right)
$$

where $\omega_{s}$ is the switching frequency in radians per second, $n$ is the transformer turns ratio, and $\phi$ is the phase-shift between $v_{p}$ and $v_{s}$. The operation parameters for the converter and the specifications for the magnetic components that will be considered in the design process are listed in Table I. For this application, a 1:1 turns ratio is considered due to the nominal dc voltage level. The equivalent inductance must be calculated in order to allow full power transfer to the battery pack in the worst operating conditions. Since grid voltage can be in the $\pm 10 \%$ range, the minimum value is selected for $V_{p}$. The dc side of the converter is supposed to support voltages in the range $320-490 \mathrm{~V}$ to properly charge and discharge the battery pack. Considering (7), the maximum value for $L$ is calculated as $44 \mu \mathrm{H}$.

\section{B. Core material and geometry}

The magnetic materials typically used in power applications are classified in ferromagnetics (iron alloys) and ferrimagnetics (ferrites). The iron alloys exhibit high saturation flux density, $B_{\text {sat }}$, while having a low electric resistivity when compared with ferrites. Laminated cores, powder iron cores, amorphous alloys, and nanocrystalline materials are examples of iron alloys categories. The FT-3M and the 2705M are examples of ferromagnetic materials available in the market.

Ferrite cores are ceramic materials having small saturation flux density, typically in the 0.25 to $0.5 \mathrm{~T}$ range [28]. However, the ferrites have a high electric resistivity allowing a much 
smaller eddy current losses. Manganese-zinc (Mn-Zn) cores are commonly used as inductors and transformers in $10 \mathrm{kHz}$ to $1 \mathrm{MHz}$ frequency range. The 3F3 and the N87 are examples of ferrites available in the market. Regarding the core geometry, $\mathrm{U}$ and $\mathrm{E}$ cores are commonly used in power applications due to the capacity for being stacked, multiplying the magnetic cross section and preserving the winding cross section.

In this design the N87 material was selected, which is a low-medium frequency ferrite appropriated for the excitation frequency employed in this application. The design of a magnetic device (inductor or transformer) must ensure that the core material does not saturate, which means that the flux density must be lower than $B_{\text {sat }}$. Core losses produce heat which increases the operating temperature and typically reduces the $B_{\text {sat }}$ limit. Therefore, it is necessary to do a tradeoff between saturation flux density and core loss [28]. From Faraday's law, the peak-to-peak flux density is:

$$
\Delta B=\frac{\lambda_{1}}{2 \cdot N_{p} \cdot A_{c}}
$$

where $\lambda_{1}$ is the flux linkage, and $A_{c}$ is the effective magnetic cross section of the core. As can be concluded by this equation, a high operating flux density leads to a reduced size of the core, since $A_{c}$ can be smaller. In other way, if the excitation frequency $f_{c}$ is increased the flux linkage is reduced, resulting in a lower operating flux density. For the N87 ferrite material, the saturation occurs for $B_{\text {sat }}=390 \mathrm{mT}$ at $100^{\circ} \mathrm{C}$ [34]. The peak flux linkage applied to the transformer primary winding is $\lambda_{1}=0.0102$ V.s. The transformer must have a minimum $L_{M}$ in order to limit the peak magnetizing current. Using (9), $L_{M, \min }$ was defined as $3 \mathrm{mH}$ to ensure a peak magnetizing current lower than $5 \%$ of $I_{L, \text { nom }}$.

$$
L_{M, \min }=\frac{\lambda_{1}}{2 \cdot I_{M, \max }} .
$$

\section{Winding type}

The more common winding types for magnetic devices are the solid round wire, rectangular wire, foil winding, and the litz-wire. Solid round wires are the most economical solutions, but its scope of application is limited to relatively low frequencies or low current windings. However, they have high skin effect and proximity effect losses that penalize efficiency. In turn, the rectangular wire allows a better fill factor, and the skin effect and proximity effect losses are decreased when compared with the solid round wire [20]. Foil winding is a particular case of a rectangular wire with a very thin layer. By making the foil thickness small compared to the skin depth is possible to reduce even more the skin effect and proximity effect losses. For a high-current application, connecting multiple layers of foil in parallel is required.

A litz-wire is made of multiple individually insulated strands twisted or woven together [8]. Eddy current effects in a winding can be significantly reduced by employing litz-wire. By choosing a strand diameter inferior to the skin depth is possible to improve the performance regarding skin effect and proximity effect losses [28]. Due to the insulation and packing materials, the window area occupied by copper in a litz-wire

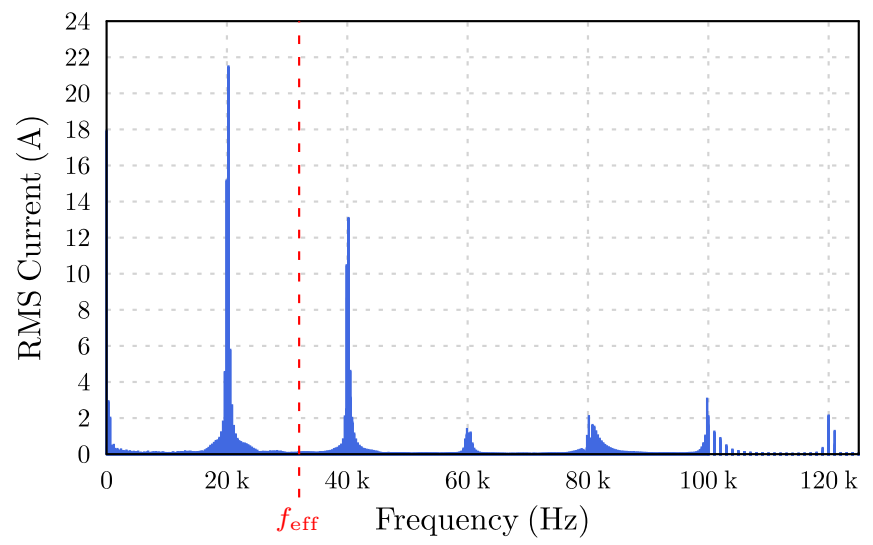

Fig. 4. Frequency spectrum of the current in the transformer primary winding.

winding will be less than that of a solid round wire of the same diameter, resulting in a higher DC resistance. Moreover, the insulation and packing materials also difficult heat dissipation contributing simultaneously for DC resistance increase.

Taking in account the employed excitation frequency and with the intent of reducing the eddy current losses, litz-wire was chosen for this application. The spectrum of $i_{L}$ is represented in Fig. 4 for operation with the parameters of Table I. As can be seen, the main component of the current appears at the switching frequency, $f_{s}=20 \mathrm{kHz}$. Since both $v_{p}$ and $v_{s}$ have a double frequency pattern, a significant component is also generated at $2 \cdot f_{s}$. Other harmonics arise at side-bands of the base frequency and its multiples due to the phase-shift operation. From (3) and considering the harmonics up to 125 $\mathrm{kHz}$, the effective frequency is calculated as $32.0 \mathrm{kHz}$. For an effective frequency between $20 \mathrm{kHz}$ and $50 \mathrm{kHz}$, a wire gauge of $36 \mathrm{AWG}$ is recommended by a litz-wire manufacture [35]. Another work [18] establishes a more restrictive relation using the skin depth to strand radius ratio: $\delta_{w} / 15<r_{0}<\delta_{w} / 30$. As a compromise between both criteria it was decided to select the 41 AWG wire gauge, resulting in $\delta_{w, 32 k H z} / r 0 \approx 10.3$. The fill factor, $\beta_{w}$, is a ratio between the winding cross section and the core window area, $A_{w}$, as defined in (10). Litz-wire has a reduced fill factor, due to serving and strand packing issues, when compared with other winding types. Values between 0.3 and 0.4 are commonly accepted for the fill factor of litz-wire windings [36]. Since the turns ratio of the HFT is unitary, an equal window distribution between primary and secondary is considered in order to reduce the cost.

$$
\beta_{w}=\frac{N \cdot \pi \cdot r_{0}^{2} \cdot N_{0}}{A_{w}}
$$

The winding arrangement is another degree of freedom that influence winding losses. If maximum efficiency is desired, primary and secondary windings must be fully interleaved [18]. Moreover, a substantial reduction in leakage inductance is obtained by interleaving the primary and secondary windings which is a critical design factor for the HFLMC. The leakage inductance referred to the primary side for magnetically symmetric arrangement of windings can be 


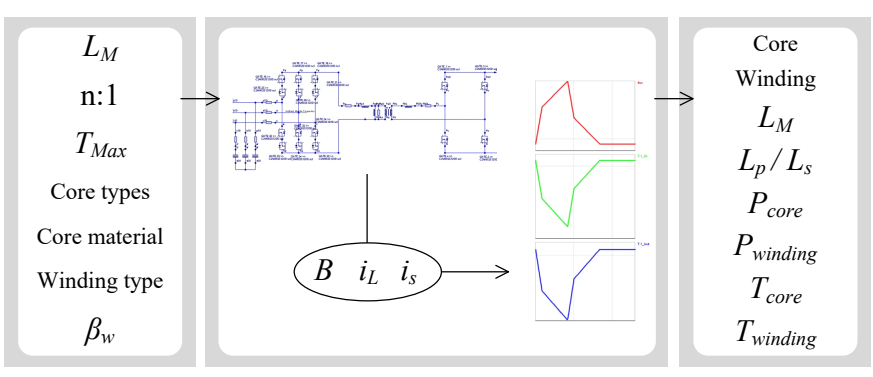

Fig. 5. Transformer design methodology.

estimated by the following [37]:

$$
L_{\text {leak }}=\frac{\mu_{0} \cdot M L T \cdot N^{2}}{p_{w}^{2} \cdot h_{w}}\left(\frac{\sum d_{w}}{3}+\sum c_{w}\right)
$$

where $\mu_{0}$ is the absolute permeability, $d_{w}$ the external diameter of the litz-wire bundle, $c_{w}$ the insulation space between the windings, $h_{w}$ the bobbin height, and $p_{w}$ is the number of insulating interspaces between the litz-wire bundles. The flux increase due to the leakage inductance is determined by (12). After this calculation it must be verified if the total flux density does not exceed the saturation limit.

$$
\Delta B_{l e a k}=\frac{L_{l e a k} \cdot I_{L, p k}}{N_{p} \cdot A_{c}} .
$$

\section{Design results and verification}

Recurring to its wide core and windings database, the software evaluates the possible combinations and presents the result in the conventional power-loss versus volume (P-V) plot. The designer must implement the complete electric circuit and respective command system in GeckoCIRCUITS [32] software. Subsequently, GeckoMAGNETICS receive $B, i_{L}$, and $i_{s}$ from simulation in order to compute the core and winding losses for each design combination. Fig. 5 shows a flowchart with the design process employing the software bundle. The input parameters for the software are: $3 \leq L_{M} \leq 10 \mathrm{mH}$, $n=1, T_{\max }=100^{\circ} \mathrm{C}$, double-E cores, N87 material, litzwire, and $0.2 \leq \beta_{w} \leq 0.4$. After evaluation of the possible design combinations, the software present the results in a $\mathrm{P}-\mathrm{V}$ plot. The design that presented the best compromise between losses and volume is detailed in Table II. Regarding the magnetic circuit, 5 stacks of EE80 cores were mounted in a custom bobbin, made of Polyphenylsulfone (PPSU) supporting temperatures up to $180^{\circ} \mathrm{C}$. The stacks are spaced by $2 \mathrm{~mm}$ to improve heat extraction from the windings. The specified peak flux density is calculated by (8) as $238 \mathrm{mT}$. From (12), the flux increase due to $L_{\text {leak }}$ is $32.7 \mathrm{mT}$. As can be concluded, the total flux density does not exceed the $273 \mathrm{mT}$ limit previously specified. A litz-wire with 1440 strands is selected which has a $5.70 \mathrm{~mm}^{2}$ cross section. The RUPALIT Safety V155 with 3 layer mylar insulation [38] from Rudolf Pack $\mathrm{GmbH}$ is chosen for this application. Each winding is composed by two litz-wire bundles connected in parallel corresponding to an effective cross section $A_{c u}=11.40 \mathrm{~mm}^{2}$. For the converter specifications of Table I, the resulting current density at nominal operation is $J_{w}=3.99 \mathrm{~A} / \mathrm{mm}^{2}$. The practical fill
TABLE II

DESIGN VALUES FOR THE POWER TRANSFORMER.

\begin{tabular}{c|c}
\hline Variable & Design value \\
\hline \hline Core & $5 \times$ EE80/38/20 \\
\hline Core material & N87 \\
\hline Effective magnetic cross section & $1950 \mathrm{~mm}^{2}$ \\
\hline Specified peak flux density & $238 \mathrm{mT}$ \\
\hline Air gap $\left(l_{g}\right)$ & $0 \mathrm{~mm}$ \\
\hline Distance between stacks & $2 \mathrm{~mm}$ \\
\hline Number of Turns $\left(N_{p}: N_{s}\right)$ & $11: 11$ \\
\hline Litz-wire $\left(N_{0} \times d_{0}\right)$ & 2 litz-wire bundles in parallel \\
\hline Winding arrangement & $2 / 1$ vertical interleaved \\
\hline Interleaving of the windings & $3.55 \mathrm{mH}$ \\
\hline Magnetizing inductance $\left(L_{M}\right)$ & $3.19 \mu \mathrm{H} / 3.19 \mu \mathrm{H}$ \\
\hline Leakage inductances $\left(L_{p} / L_{s}\right)$ & $6.9 \mathrm{~m} \Omega$ \\
\hline DC Resistance $\left(R_{d c}\right)$ & $80.0 \times 77.0 \times 143.5 \mathrm{~mm}$ \\
\hline Dimensions & $0.884 \mathrm{dm} 3$ \\
\hline Boxed Volume &
\end{tabular}

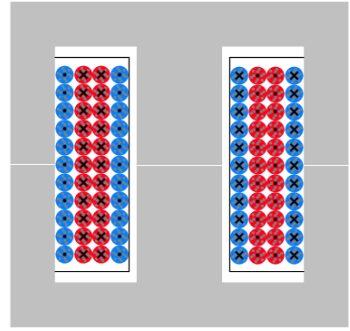

(a)

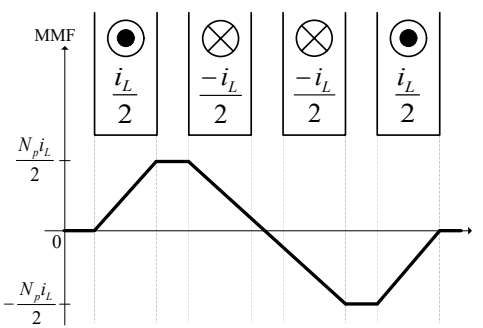

(b)
Fig. 6. (a) Cut of the transformer with the winding arrangement. (b) MMF distribution versus position of the interleaved windings inside the core window.

factor is calculated from (10) as $\beta_{w}=0.28$. The mean length turn for the stacked cores is $M L T=0.372 \mathrm{~m}$. Considering the effective cross section and the number of turns, the dc resistance of each winding at $100^{\circ} \mathrm{C}$ is $R_{d c}=6.9 \mathrm{~m} \Omega$. By (4) the ac copper loss factor at $f_{\text {eff }}$ is $F_{a c}=1.035$. Taking in account these results, from (6) the estimated winding losses of each winding is $P_{w, \text { hft }}=14.9 \mathrm{~W}$ which is very close to the $15.1 \mathrm{~W}$ calculated by the software. This difference is related to some minor aspects that are neglected by the $F_{a c}$ factor.

Fig. 6(a) shows the winding arrangement where it is clear the interleaving of the secondary winding inside the primary winding. The proximity effect losses are proportional to the square of the magnetic flux (MMF) in the winding. Fig. 6(b) depicts the MMF for this transformer. Since the interleaving strategy reduces the MMF peak by half, the proximity effect losses are reduced by a factor of four. Simultaneously, from (11) can be concluded that the leakage inductance has onefourth the value of the simple winding arrangement.

A 3D CAD model of the transformer is represented in Fig. 7(a). This is a compact design and achieves a power density of $11.3 \mathrm{~kW} / \mathrm{dm}^{3}$. The power loss distribution between core and windings is depicted in Fig. 7(b). Winding losses are divided in proximity effect losses, skin effect losses and dc bias current. The total losses of this design are $46.6 \mathrm{~W}$ corresponding to an efficiency of $99.53 \%$. 


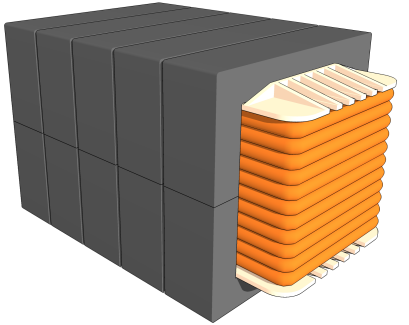

(a)

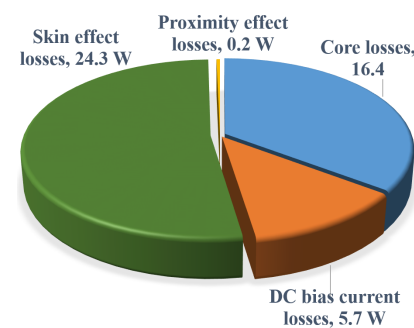

(b)
Fig. 7. (a) 3D CAD model of the transformer. (b) Core and winding losses distribution in the transformer.

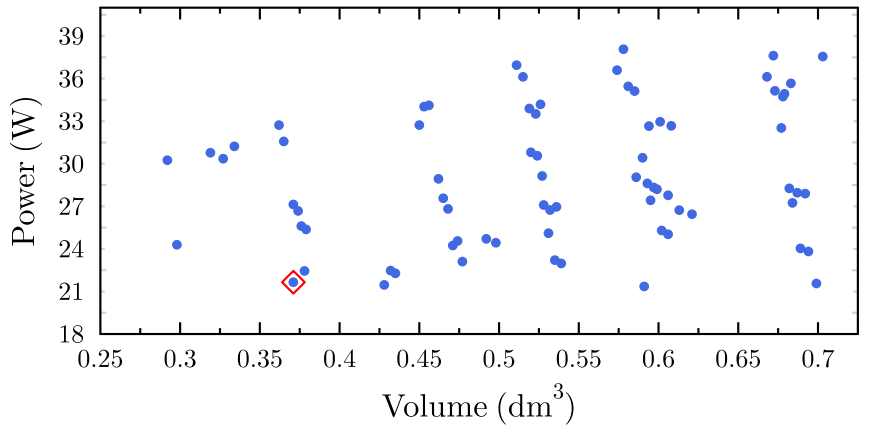

Fig. 8. P-V plot of the link inductor design.

\section{DESIGN OF LINK INDUCTOR}

The additional inductance required for the HF-link operation must be provided by the link inductor. The projected transformer has a total leakage inductance of $6.4 \mu \mathrm{H}$. Thus, from (1) the link inductor must be designed to have at least $37.6 \mu \mathrm{H}$ at $i_{L, p k}$. Since the inductance varies with the current and the temperature, the link inductor is designed with a nominal value of $L_{n o m}=40 \mu \mathrm{H}$. Since this inductor will conduct the same current as the transformer and will have equal excitation frequency, the 41 AWG litz-wire is selected for the conductor. For practical reasons, the design is restricted to the same number of strands. Regarding the core, double-E and ELP cores are preferred in order to provide a compact inductor. The flowchart for inductor design methodology is very similar of the one in Fig. 5. The input parameters for the software are: $L_{n o m}=40 \mu \mathrm{H}, L_{\text {link }} \geq 0.90 \cdot L_{n o m}$ at $i_{L, p k}, T_{\max }=100^{\circ} \mathrm{C}$, double-E and ELP cores, N87 material, and $1440 \times 71 \mu \mathrm{m}$ litz-wire. The P-V plot provided by the software after the optimization is depicted in Fig. 8. As can be seen, the space of results is large considering the volume and power losses range. The selected design is marked in this plot and the respective design values are listed in Table III. Regarding the magnetic circuit, 2 stacks of EE70 cores can be mounted in the available commercial bobbin. The stacks are spaced by $1 \mathrm{~mm}$ to improve heat extraction from the windings. An air gap of $5.6 \mathrm{~mm}$ is necessary to increase the reluctance and prevent core saturation. The obtained inductance at peak current is $L_{l i n k, p k}=38.1 \mu \mathrm{H}$. The peak flux density is calculated as $\hat{B}_{\max }=360 \mathrm{mT}$ which has a smaller margin for the limit of the $\mathrm{N} 87$ ferrite material. However, the selected design is accepted since the core temperature is $73^{\circ} \mathrm{C}$. The

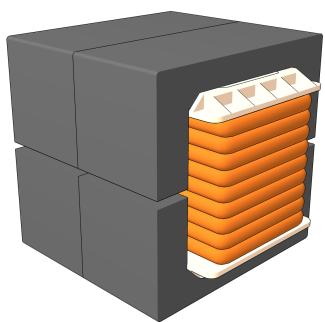

(a)

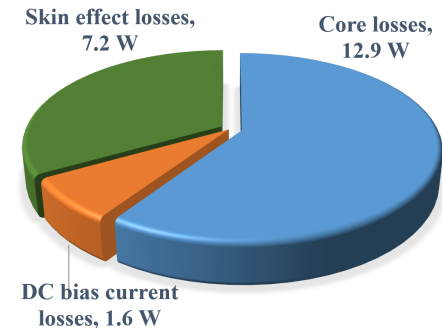

(b)
Fig. 9. (a) 3D CAD model of the link inductor. (b) Core and winding losses distribution in the link inductor.

TABLE III

DESIGN VALUES FOR THE LINK INDUCTOR.

\begin{tabular}{|c|c|}
\hline Variable & Design value \\
\hline Core & $2 \times \mathrm{EE} 70 / 33 / 32$ \\
\hline Core material & N87 \\
\hline Effective magnetic cross section & $1366 \mathrm{~mm}^{2}$ \\
\hline Specified peak flux density & $360 \mathrm{mT}$ \\
\hline Air gap $\left(l_{g}\right)$ & $5.6 \mathrm{~mm}$ \\
\hline Distance between stacks & $1 \mathrm{~mm}$ \\
\hline Number of Turns $(N)$ & 9 \\
\hline Litz-wire $\left(N_{0} \times d_{0}\right)$ & $1440 \times 71 \mu \mathrm{m}$ \\
\hline Winding arrangement & 2 litz-wire bundles in parallel \\
\hline Inductance $\left(L_{\text {link }}\right)$ & $40.2 \mu \mathrm{H}$ \\
\hline DC Resistance $\left(R_{d c}\right)$ & $3.9 \mathrm{~m} \Omega$ \\
\hline Dimensions & $70.5 \times 68.8 \times 82.0 \mathrm{~mm}$ \\
\hline Boxed Volume & $0.398 \mathrm{dm}^{3}$ \\
\hline
\end{tabular}

winding is composed by two litz-wire bundles connected in parallel, resulting in a current density at nominal operation of $J_{w}=3.99 \mathrm{~A} / \mathrm{mm}^{2}$. The practical fill factor is calculated from (10) as $\beta_{w}=0.22$. The mean length turn for the stacked cores is $M L T=0.251 \mathrm{~m}$. Considering the effective cross section and the number of turns, the dc resistance of each winding at $100^{\circ} \mathrm{C}$ is $R_{d c}=3.84 \mathrm{~m} \Omega$. By (4) the ac copper loss factor at $f_{\text {eff }}$ is $F_{a c}=1.041$. Taking in account these results, from (6) the winding losses are estimated as $P_{w \text {,link }}=8.3 \mathrm{~W}$ which is also very close to the $8.8 \mathrm{~W}$ calculated by the software.

A 3D CAD model of the link inductor is represented in Fig. 9(a). This design achieves a power density of 25.1 $\mathrm{kW} / \mathrm{dm}^{3}$. The power loss distribution between core and winding is depicted in Fig. 9(b). Winding losses are divided in skin effect losses and dc bias current. The proximity effect losses are negligible. The total losses of this design are 21.6 $\mathrm{W}$ corresponding to an efficiency of $99.78 \%$.

\section{CONCLUSION}

An approach to design the transformer and the link inductor for the HFLMC has been presented in this paper. The models for the core and winding losses characterization have been reviewed and selected to guide the design. Core geometry and materials are compared as also the different conductor types. The most appropriate options for this specific application are selected and are inputs for the software. The best result from the optimization process is selected and validated using 
the previously presented models. This design process was a challenging task since the beginning, having in mind the nonconventional waveform of the applied voltage. The worstcase scenario is taking always into account resulting in robust magnetic components. The high currents circulating in the windings require the use of high gauge wires, in this case litz to avoid excessive losses. The EE80 core is a good option to accomodate this large windings since it has a large winding area/magnetic area ratio. This ratio is much lower in the EE70 cores, which benefits the inductance factor, being much more adequate for inductors. A $10 \mathrm{~kW} / 20 \mathrm{kHz}$ transformer plus a link inductor are designed using this strategy. The final results of the set designed are impressive, achieving a combined efficiency at full load of $99.32 \%$.

\section{ACKNOWLEDGMENT}

This work is partially funded by National Funds through FCT - Science and Technology Foundation, through the scholarship SFRH/BD/89327/2012, and is being carried out as a part of the SENSIBLE project (Storage ENabled SustaInable energy for BuiLdings and communitiEs - www.h2020-projectsensible.eu) that has received funding from the European Union's Horizon 2020 - The EU Framework Programme for Research and Innovation 2014-2020, under grant agreement No.[645963].

\section{REFERENCES}

[1] S. S. Williamson, A. K. Rathore, and F. Musavi, "Industrial Electronics for Electric Transportation: Current State-of-the-Art and Future Challenges," IEEE Trans. Ind. Electron., vol. 62, no. 5, pp. 3021-3032, 2015.

[2] B. K. Bose, "Global Energy Scenario and Impact of Power Electronics in 21st Century," IEEE Trans. Ind. Electron., vol. 60, no. 7, pp. 2638 2651, 2013

[3] B. M. Grainger, G. F. Reed, A. R. Sparacino, and P. T. Lewis, "Power Electronics for Grid-Scale Energy Storage," Proc. IEEE, vol. 102, no. 6, pp. 1000-1013, 2014.

[4] M. Yilmaz and P. T. Krein, "Review of Battery Charger Topologies, Charging Power Levels, and Infrastructure for Plug-In Electric and Hybrid Vehicles," IEEE Trans. Power Electron., vol. 28, no. 5, pp. 21512169, 2013.

[5] M. Vasiladiotis and A. Rufer, "A Modular Multiport Power Electronic Transformer With Integrated Split Battery Energy Storage for Versatile Ultrafast EV Charging Stations," IEEE Trans. Ind. Electron., vol. 62, no. 5, pp. 3213-3222, 2015.

[6] H. A. Mantooth, M. D. Glover, and P. Shepherd, "Wide Bandgap Technologies and Their Implications on Miniaturizing Power Electronic Systems,' IEEE J. Emerg. Sel. Topics Power Electron, vol. 2, no. 3, pp. 374-385, 2014.

[7] M. S. Rauls, D. W. Novotny, and D. M. Divan, "Design considerations for high-frequency coaxial winding power transformers," IEEE Trans. Ind. Appl., vol. 29, no. 2, pp. 375-381, 1993.

[8] C. R. Sullivan, "Optimal choice for number of strands in a litz-wire transformer winding," IEEE Trans. Power Electron., vol. 14, no. 2, pp. 283-291, 1999.

[9] T. Kjellqvist, S. Norrga, and S. Ostlund, "Design considerations for a medium frequency transformer in a line side power conversion system," in 35th Ann. IEEE Power Electron. Spec. Conf. (PESC '04), vol. 1, pp. 704-710 Vol.1.

[10] D. Aggeler, J. Biela, and J. W. Kolar, "A compact, high voltage $25 \mathrm{~kW}$, $50 \mathrm{kHz}$ DC-DC converter based on SiC JFETs," in 23th Ann. IEEE Appl. Power Electron. Conf. Expo. (APEC '08), pp. 801-807.

[11] J. Liu, L. Sheng, J. Shi et al., "Design of High Voltage, High Power and High Frequency Transformer in LCC Resonant Converter," in 24th Ann. IEEE Appl. Power Electron. Conf. Expo. (APEC '09), pp. 1034-1038.

[12] C. k. Leung, S. Dutta, S. Baek, and S. Bhattacharya, "Design considerations of high voltage and high frequency three phase transformer for Solid State Transformer application," in IEEE Energy Convers. Congress Expo. (ECCE '10), pp. 1551-1558.
[13] H. Fan and H. Li, "High-Frequency Transformer Isolated Bidirectional DC-DC Converter Modules With High Efficiency Over Wide Load Range for 20 kVA Solid-State Transformer,' IEEE Trans. Power Electron., vol. 26, no. 12, pp. 3599-3608, 2011.

[14] J. Muhlethaler, J. Biela, J. W. Kolar, and A. Ecklebe, "Improved Core-Loss Calculation for Magnetic Components Employed in Power Electronic Systems," IEEE Trans. Power Electron., vol. 27, no. 2, pp. 964-973, 2012

[15] G. Ortiz, M. Leibl, J. W. Kolar, and O. Apeldoorn, "Medium frequency transformers for solid-state-transformer applications - Design and experimental verification," in IEEE Int. Conf. Power Electron. Driv. Syst. (PEDS '13), pp. 1285-1290.

[16] A. D. Nardo, G. D. Capua, and N. Femia, "Transformer Design for Isolated Switching Converters Based on Geometric Form Factors of Magnetic Cores," IEEE Trans. Ind. Electron., vol. 60, no. 6, pp. 21582166, 2013.

[17] C. R. Sullivan and R. Y. Zhang, "Simplified design method for litz wire," in 29th Ann. IEEE Appl. Power Electron. Conf. Expo. (APEC '14), pp. 2667-2674

[18] E. L. Barrios, A. Ursua, L. Marroyo, and P. Sanchis, "Analytical Design Methodology for Litz-Wired High-Frequency Power Transformers,' IEEE Trans. Ind. Electron., vol. 62, no. 4, pp. 2103-2113, 2015.

[19] C. Gammeter, F. Krismer, and J. Kolar, "Comprehensive Conceptualization, Design, and Experimental Verification of a Weight-Optimized All-SiC 2kV/700V DAB for an Airborne Wind Turbine," IEEE J. Emerg. Sel. Topics Power Electron, vol. PP, no. 99, pp. 1-1, 2015.

[20] J. Muhlethaler, "Optimal Design of Inductive Components Based on Accurate Loss and Thermal Models," in 30th Ann. IEEE Appl. Power Electron. Conf. Expo. (APEC'15).

[21] P. W. Wheeler, J. Rodriguez, J. C. Clare et al., "Matrix converters: a technology review," IEEE Trans. Ind. Electron., vol. 49, no. 2, pp. 276$288,2002$.

[22] J. W. Kolar, T. Friedli, J. Rodriguez, and P. W. Wheeler, "Review of Three-Phase PWM AC-AC Converter Topologies," IEEE Trans. Ind. Electron., vol. 58, no. 11, pp. 4988-5006, 2011.

[23] T. Friedli, J. W. Kolar, J. Rodriguez, and P. W. Wheeler, "Comparative Evaluation of Three-Phase AC-AC Matrix Converter and Voltage DCLink Back-to-Back Converter Systems," IEEE Trans. Ind. Electron., vol. 59, no. 12, pp. 4487-4510, 2012.

[24] G. Rizzoli, L. Zarri, M. Mengoni et al., "Comparison between an ACDC matrix converter and an interleaved DC-DC converter with power factor corrector for plug-in electric vehicles," in IEEE Int. Elect. Vehicle Conf., 2014, pp. 1-6.

[25] D. Varajao, L. M. Miranda, and R. E. Araujo, "AC/DC Converter with Three To Single Phase Matrix Converter, Full-Bridge AC/DC Converter and HF Transformer," International Patent Application, WO2016024223, 18 February 2016.

[26] _ - "Towards a new technological solution for Community Energy Storage," in 16th European Conf. Power Electron. Appl. (EPE '14), 2014, pp. 1-10.

[27] H. Akagi, T. Yamagishi, N. M. L. Tan et al., "Power-Loss Breakdown of a 750-V 100-kW 20-kHz Bidirectional Isolated DC-DC Converter Using SiC-MOSFET/SBD Dual Modules," IEEE Trans. Ind. Appl., vol. 51, no. 1 , pp. 420-428, 2015.

[28] R. W. Erickson and D. Maksimovic, Fundamentals of Power Electronics, 2nd ed. Springer, 2001.

[29] C. P. Steinmetz, "On the law of hysteresis," Proc. IEEE, vol. 72, no. 2, pp. 197-221, 1984.

[30] J. Muhlethaler, J. Biela, J. W. Kolar, and A. Ecklebe, "Core Losses Under the DC Bias Condition Based on Steinmetz Parameters," IEEE Trans. Power Electron., vol. 27, no. 2, pp. 953-963, 2012.

[31] J. Muhlethaler, J. W. Kolar, and A. Ecklebe, "Loss modeling of inductive components employed in power electronic systems," in IEEE Int. Conf. Power Electron. and ECCE Asia (ICPE \& ECCE '11), pp. 945-952.

[32] Gecko-Simulations AG - GeckoCIRCUITS \& GeckoMAGNETICS. [Online]. Available: www.gecko-simulations.com

[33] J. Muhlethaler, "Modeling and multi-objective optimization of inductive power components," Ph.D. dissertation, 2012.

[34] TDK, "SIFERRIT material N87," 2015/03/10

[35] New England Wire Technologies, "Litz Wire Theory," 2015/03/12.

[36] V. Valchev and A. Van den Bossche, Inductors and Transformers for Power Electronics. CRC Press, 2005.

[37] R. Doebbelin and A. Lindemann, "Leakage Inductance Determination for Transformers with Interleaving of Windings," Progress In Electromagnetics Research (PIERS), vol. 6, no. 6, pp. 527-531, 2010.

[38] Pack Feindraehte, “Technical Data Rupalit Litz Wire,” 2015/03/12. 